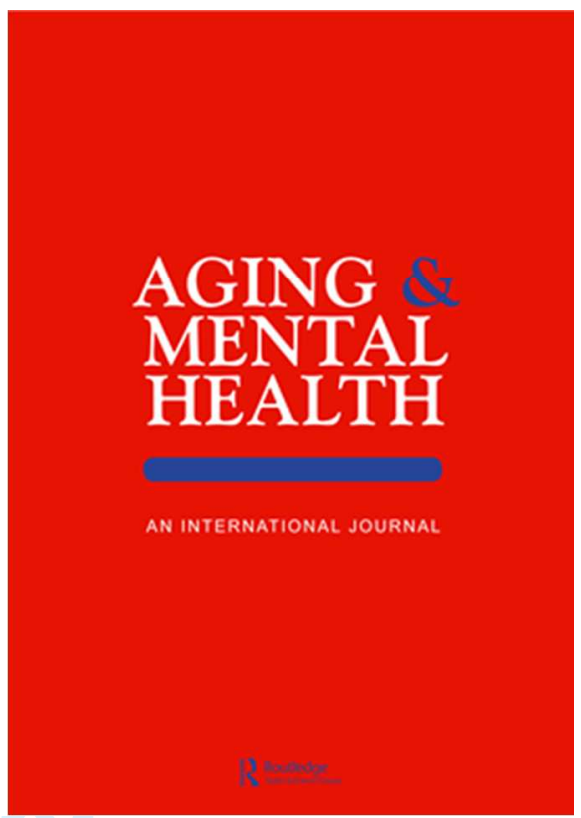

Forgiveness and late life functioning:

The mediating role of finding ego-integrity

\begin{tabular}{|r|l|}
\hline Journal: & Aging and Mental Health \\
\hline Manuscript ID & CAMH-2017-0255.R1 \\
\hline Manuscript Type: & Original Article \\
\hline Keywords: & $\begin{array}{l}\text { Forgiveness, Late life functioning, Integrity-despair, Erikson, residential } \\
\text { care setting }\end{array}$ \\
\hline
\end{tabular}

SCHOLARONE ${ }^{m}$

Manuscripts 
1

2

3

4

5

6

7

8

9

10

11

12

13

14

15

16

17

18

19

20

21

22

23

24

25

26

27

28

29

30

31

32

33

34

35

36

37

38

39

40

41

42

43

44

45

46

47

48

49

50

51

52

53

54

55

56

57

58

59

60
Forgiveness and late life functioning:

The mediating role of finding ego-integrity
1

URL: http:/mc.manuscriptcentral.com/camh 
Forgiveness and late life functioning

\section{Forgiveness and late life functioning: The mediating role of finding ego- integrity}

Objectives: This study seeks (1) to replicate previous findings on the mediating effect of integrity/despair in the relation between forgiveness and depression in an elderly population, and (2) to extend these findings to other aspects of functioning, namely life satisfaction and subjective health. Both aims were studied in a sample of residential elderly.

Methods: Residential elderly ( $\mathrm{n}=329, \mathrm{M}=87$ years) filled out questionnaires on forgivingness, depressive symptoms, life satisfaction, subjective health and the developmental task of integrity/despair. Structural equation modeling was used to test the mediational role of integritydespair in the relation between forgivingness and the aspects of functioning. Direct and indirect effects are tested.

Results: The results confirmed earlier findings stating that forgivingness and depression are negatively associated in residential elderly and that the developmental task of finding integrity and avoiding despair is significant mediator in this relationship. A similar pattern of mediational associations was found for life satisfaction. However, for subjective health only a direct effect between forgiveness and subjective health was found, whereas the developmental task of integrity and despair did not function as an underlying mechanism.

Discussion: Framed within a life span perspective, we showed that the developmental task of finding a balance between integrity and despair is an important intrapersonal mechanism through which forgivingness is related with depressed feelings and life satisfaction for residential elderly. A different mechanism might explain the direct effect between forgiveness and subjective health.

Keywords: Forgiveness, Late Life Functioning, Integrity-Despair 
Forgiveness and late life functioning

\section{Introduction}

Late life is a period in which individuals are increasingly confronted with challenges such as a poor functional status, cognitive decline, or psychosocial changes including bereavement and loneliness. These challenges can negatively impact late life functioning which is often reflected in mental health problems (e.g., increased depressive symptoms) or compromised well-being (e.g., lower life satisfaction and happiness). Identifying factors that could buffer the negative impact of these age-related challenges might offer insight into the process of successfully aging and might be implemented in treatment programs stimulating late life wellbeing. Identifying these factors has been a genuine interest of positive psychology (Vaillant, 2008). One of the potential protective factors that has recently received attention is forgiveness (Dezutter, Toussaint, \& Leijssen, 2016).

Interest in the subject of forgiveness was sparked in the late eighties and has surged since the dawn of the new millennium (Friedberg, Tuvia, \& Cha, 2015) - in line with the shift of focus towards human flourishing that came with the advent of positive psychology. Experts agree that forgiveness is a broad multifaceted phenomenon (Fehr et al., 2010; Thompson et al., 2005), but they differ in opinion on the essential aspects of the construct. Most researchers agree that forgiveness involves a complex process of affective, cognitive, and often, but not necessarily, motivational and behavioural changes consequential to an interpersonal offense (Enright \& the Human Development Study Group, 1996); making it an intrapersonal, and possibly an interpersonal process (McCullough, Pargament, \& Thoresen, 2000). It comprises letting go of one's right to retribution and unforgiving emotions, and -usually - also the promotion of positive prosocial cognitions and emotions (e.g., compassion, love, sympathy) towards the offender (Worthington \& Wade, 1999). Researchers have shown special interest in trait forgiveness. According to Brown (2003) trait forgiveness can be defined as "a global disposition, across situations and relationships" (p. 759), and this is often described as forgivingness in the literature. These relatively stable individual differences in forgiveness de facto do appear to exist (Brown \& Phillips, 2005).

\section{Forgiveness and late life functioning}

The link between forgiveness and mental health has been one of the main focuses in the forgiveness literature. As Dezutter and colleagues (2013) point out, supporting factors as forgiveness deserve special attention, since they protect against depressive symptoms while at 
the same time boosting life satisfaction, both of which predict mortality independently in aging individuals (Collins, Glei, \& Goldman, 2009). Research has indeed found positive associations between forgiveness and psychological well-being (Cox, Bennett, Tripp, \& Aquino, 2012; Green, DeCourville, \& Sadava, 2012), including life satisfaction (Brown \& Phillips, 2005; Thompson et al., 2005), self-esteem (Torges et al., 2013), happiness (Maltby, Day, \& Barber, 2005), and optimism (Hill \& Allemand, 2011). However, not all studies support this link between forgiveness and well-being. For example, McCullough and colleagues (2001) did not find a beneficial causal effect of forgiving one's offenders on subjective well-being in a small student sample.

Research has not only connected forgiveness to mental health, but also to physical and subjective health. Seybold et al. (2001) examined the connection with physiological markers of health in 68 adult men. They found lower hematocrit and white blood cell counts in those scoring higher on forgiveness. They also found a negative association with poor health habits. Lawler et al. (2005) found significant correlations between forgiveness and physical symptoms, medications used, sleep quality, fatigue, and somatic complaints. Several studies have found negative associations between forgiveness levels and blood pressure (Friedberg, Suchday, \& Shelov, 2007; Witvliet, Ludwig, \& Vander Laan, 2001), however some studies have not (e.g., Seybold et al., 2001). Evidence also suggests an inverse relationship between forgiveness and pain (Carson et al., 2005; Öffenbacher et al., 2016).

A multitude of studies have linked forgiveness to subjective health. Silton, Flannelly, Galek, and Flannelly (2010) found an indirect effect of forgiveness on subjective health through hostility in a sample of 1327 U.S. adults. In a smaller sample of 331 Czech respondents, Tenklova, and Slezackova (2016) found a significant link between forgiveness and the subjective assessment of general health. However, some studies failed to find this relationship (for forgiveness of others: Wilson, Milosevic, Carroll, Hart, \& Hibbard, 2008; for trait forgivingness: Green et al., 2012; for forgiveness of others and self-forgiveness in older adults: Ermer \& Proulx, 2015).

Especially germane to the current study is the research on age differences in forgivingness and in the association between forgiveness and health. Some studies suggest that forgiveness might be a dynamic tendency, with people becoming more forgiving with age (e.g., Steiner, Allemand, \& McCullough, 2011). For example, a study by Toussaint, Williams, Musick, and Everson (2001) in an U.S. probability sample indicated that middle-aged and older adults were more willing to forgive others respective to younger individuals. Although there is no consensus in the literature on this issue (e.g., Fehr et al., 2010; Hill \& Allemand, 2011), there 
seems to be some agreement on the theoretical foundation underlying the association between forgiveness and age (Krause \& Hayward, 2015). First, since elderly adults have already experienced a lifetime's worth of interpersonal problems and challenging situations, it seems likely they have gained knowledge on the best ways of dealing with them (Charles \& Carstensen, 2010). Aged individuals could have learned to see forgiveness as an especially constructive asset in this regard, and thus make more frequent use of it than younger individuals.

Second, theories of aging such as Tornstam's (2005) theory of gerotranscendence or Carstensen's (1992) socioemotional selectivity theory contend that late life is characterized by a shift in focus, in which forgiveness could play an important role. Tornstam claims that people evolve over the course of the lifespan from a more self-centered to a more transcendent, altruistic perspective (Tornstam, 2005). Evidence of this can for example be found in the work of Van Lange, Otten, De Bruin, and Joireman (1997). Their study showed a more prosocial attitude in older adults compared to younger individuals. This shift in metaperspective is also reflected in a study by Sorkin and Rook (2006) that indicated that preserving goodwill is the main goal in dealing with interpersonal trouble for aging individuals. The socioemotional selectivity theory posits that with the perception of remaining time as being limited, people start prioritizing emotion-focused and meaningful goals (Carstensen, 1992). This translates into attributing greater importance to close relationships. It is easy to see how this could entail being more likely to forgive others. Research by Cheng and Yim (2008) showed a positive connection between limited future time perspective and forgiveness, whereas a study by Allemand, Hill, Ghaemmaghami, and Martin (2012) indicated that future time perspective moderates the relationship between forgivingness and well-being.

Not only does forgiveness seem to increase with age, older adults are also more likely than younger individuals to benefit from the positive health consequences that are associated with it (Allemand, 2008; Toussaint et al., 2001). On the downside, older adults also appear to be more at risk of suffering from unforgiveness (Ermer \& Proulx, 2015; Toussaint et al., 2001) or low forgivingness (Allemand et al., 2012). Research suggests that the salience of forgiveness in this age category could be linked to the vital importance of social ties in a life stage where social networks diminish (Lang \& Carstensen, 1994) while being increasingly valued (Ingersoll-Dayton, Torges, \& Krause, 2010). Close personal relationships can be a pathway to a more meaningful life, and, in turn, a more healthy life (Wong, 2012). 
Forgiveness and late life functioning

\section{Optimal functioning through ego-integrity}

One way of understanding the interplay between forgiveness, meaning and optimal functioning in late life, can be found in Erikson's (1982) theory of human development. According to Erikson, each individual goes through eight different stages in life, each one building on the other, and each of them linked to a certain psychosocial developmental challenge. This process starts at birth and encompasses the entire life span. When someone fails to resolve one of these crises, it becomes more difficult - but not impossible - to resolve the subsequent challenges; and when one of these developmental tasks has been worked through, it can still return later in life, when specific circumstances make it salient again.

In the final stage of life, the focal task is balancing integrity with despair. According to Erikson, Erikson, and Kivnick (1994), this involves "a renewed and old-age-specific willingness to remember and review earlier experiences" (p. 40). Confronted with the finitude of their own existence, older adults survey their lives, trying to come to terms with the inalterability of the past and figuring out what it all means. This process of deep introspection can lead to "the acceptance of one's own and only life cycle [...] as something that had to be [...]" (Erikson, 1959, p. 98), resulting in a more integrated view of their lives, and a high level of self-acceptance. This state of being is what Erikson refers to as ego-integrity. Other older adults keep struggling with painful memories and unresolved issues, making them condemn their lives as being meaningless, and leading to a state of despair. Erikson linked the successful balancing of the integrity/despair tension in late life to the well-being of older adults, which has since been supported by research. For example, Hearn et al. (2012) showed a positive relation between integrity and perceived health, while despair was positively correlated to depression, and Lowis and Raubenheimer (1997) found a positive relationship between resolving the integrity/despair developmental task and life satisfaction.

Since a successful life review implies getting over old hurts, it seems likely that more forgiving older adults will be more likely to experience ego-integrity and thus also be more likely to reap the mental health benefits that come with resolving this developmental task, as well as the benefits that come with forgivingness. A forgiving attitude might facilitate the process of coming to terms with regrets, painful experiences, and hatred feelings, and resolving and past conflicts which are central components in the developmental task of achieving ego-integrity. Achieving ego-integrity is, on its turn, related with better psychological functioning (e.g., Westerhof, Bohlmeijer, \& McAdams, 2015). A recent study by Dezutter et al. (2016) confirmed this idea. The authors found a negative relation between 
forgivingness of others and depressive symptoms in community-dwelling and residential elderly individuals in Belgium, and the resolution of the developmental task of integrity/despair mediated this relationship significantly. The current study seeks to replicate these findings, and extend them so as to include the connection between forgiveness of others and both life satisfaction and subjective health. More precisely, this study seeks (1) to replicate previous findings on the mediating effect of integrity/despair in the relation between forgiveness of others and depression in an elderly population (Dezutter et al., 2016), and (2) to extend these findings to other aspects of functioning, namely life satisfaction and subjective health. As to this extension, previous research supports our expectation of a positive relationship of forgiveness with satisfaction and health (e.g., Tenklova \& Slezackova, 2016). However, conflicting results have been found (e.g., Green et al., 2012).

\section{Method}

\section{Participants and Procedure}

The sample consisted of 329 elderly adults living in 27 nursing homes in XXX (- redacted for blind review). Six psychology students pursuing master's degrees and two $\mathrm{PhD}$ students contacted nursing homes in their living areas and asked for cooperation in the study. An informational letter to the boards introduced the study as an investigation on how elderly people cope with the challenges they face and how they experience meaning in their lives. Exclusion criteria were cognitive, hearing, and/or speech impairment. Informed consent was obtained, the voluntary nature of participation was emphasized, and confidentiality was guaranteed. Contact information was provided, and participants were encouraged to make use of it if they had any later questions. The study received approval from the XXX (- redacted for blind review) ethical committee (SMEC code G- 201507 285).

Researchers visited the elderly adults in their own private rooms to fill out the questionnaires. Because of the age of the participants, questions were read aloud and answers and comments were written down by the researcher. After completion of the questionnaire, participants were asked for remarks or questions, and thanked for their willingness to participate.

Participants were aged 65 to 99 , with an average of 87 years $(S D=6.04), 71 \%$ of the sample was female. Regarding civil state, $5 \%$ identified as single, $11 \%$ as married, $79 \%$ as widowed, $4 \%$ as divorced and $1 \%$ did not provide an answer. For $14 \%$ of the sample the highest level of education was primary school, for $75 \%$ secondary school, and $10 \%$ had 
Forgiveness and late life functioning

higher education ( $1 \%$ did not provide an answer). The majority of the sample was Catholic (57\%), 14\% were Christian, 14\% were believers without any church affiliation, $12 \%$ were nonbelievers, $1 \%$ were others and $2 \%$ left the question open.

\section{Instruments}

Forgiveness. Trait forgiveness (forgiveness of others) was measured with the Tendency to Forgive Scale (TTF; Brown, 2003). The TTF consists of four Likert-scaled items on which participants indicate how they customarily respond when they are offended by someone, either by letting go or holding on to one's offense experiences (e.g., "I have a tendency to harbor grudges"). The item score ranges from 1 (totally disagree) to 4 (totally agree).

Ego-integrity/despair. A shortened version of the ego-integrity/despair measure developed by Van Hiel and Vansteenkiste (2009) was used (Dezutter et al., 2016). This measure has two subscales: 'ego-integrity' (4 items, e.g., "I can accept faults and missed opportunities") and 'despair' (5 items, e.g., "I look back upon my life with a feeling of discontent and regret"), rated on a 5-point Likert scale. Both scales were related in meaningful ways to measures of older adults' self-esteem, well-being and depressive symptoms (Van Hiel \& Vansteenkiste, 2009). Item scores range from 1 (totally disagree) to 4 (totally agree).

Depressive symptoms. The nursing home version of the Geriatric Depression Scale (GDS; Jongenelis et al., 2007) was used, consisting of 8 questions (e.g., "Do you feel helpless?"), scored yes (1) or no (0). Higher scores are indicative of a depressive disorder. The scale has been shown to be internally consistent $(\alpha=.80)$ with high sensitivity rates for both major (96.3\%) and minor (83\%) depressive disorder (Jongenelis et al., 2007).

Life satisfaction. The Satisfaction With Life Scale (SWLS; Diener, Emmons, Larsen, \& Griffin, 1985) measures global life satisfaction and consists of five items (e.g., "In most ways, my life is close to my ideal") rated on a scale ranging from 1 (totally disagree) to 4 (totally agree). The scale has been shown to be internally consistent $(\alpha=.88)$ and is widely used.

Subjective health. To measure subjective health, two items of the self-assessed general health scale were used (Lee, 2000) assessing global health ("Would you say your health in general is excellent, good, fair, or poor?") and taking care of health ("How good a job do you feel you are doing in taking care of your health? Would you say excellent, very good, good, fair, or poor?"). In a sample of community dwelling elderly, this scale was predictive of functional decline and mortality (Lee, 2000). The scale is scored so that higher values indicate better self-assessed health. 
Forgiveness and late life functioning

For the measurement of forgiveness, ego-integrity/despair, and life satisfaction is the original 7-point Likert scale transformed to a 4-point Likert scale to reduce the answering-burden for our participants. Cronbach's alpha's of all the study scales can be found in Table 1 . The measurements of forgiveness, life satisfaction and subjective health are translated to Dutch in a back-translation procedure. The measurements of ego-integrity/despair and depressive symptoms are available in Dutch.

\section{Results}

Correlational analyses were performed with SPSS (24.0). Forgiveness of others was significantly correlated to all variables (Table 1). The association with depressive symptoms and despair was negative, whereas the association between forgiveness of others and life satisfaction, integrity and subjective health was positive, which is in line with the expectations. Also as expected, integrity showed a negative relationship with depressive symptoms, and a positive relationship with life satisfaction and subjective health. Despair showed an opposite pattern of associations.

Structural equation modelling in Mplus 7.4 (Muthén \& Muthén, 2015) was used to simultaneously examine the paths between forgiveness of others and depression, life satisfaction and subjective health. First, a direct effects model of forgiveness of others on depression, life satisfaction and subjective health was tested. The outcome variables were allowed to correlate. This resulted in a fully saturated model. In line with the expectations, forgiveness of others was negatively related with depression $(\beta=-.31, p<.001)$ and positively related with life satisfaction $(\beta=.31, p<.001)$ and subjective health $(\beta=.18, p<$ $.01)$. Next, a full mediational model was tested in which forgiveness of others was indirectly related to depression, life satisfaction and subjective health through integrity and despair. The model allowed for correlations between integrity and despair, as well as between the outcome variables. This model didn't fit the data well, $\chi^{2}(3)=17.63, \mathrm{p}<.001, \mathrm{RMSEA}=.125(90 \%$ C.I. $=[.08 ; .18]), \mathrm{CFI}=.96, \mathrm{SRMR}=.05$. Higher levels of forgiveness were associated with higher levels of integrity $(\beta=.23, p<.001)$ and lower levels of despair $(\beta=-.26, p<.001)$. Higher levels of integrity were associated with lower levels of depression $(\beta=-.26, p<.001)$ and higher levels of life satisfaction $(\beta=.23, p<.001)$. Higher levels of despair were associated with higher levels of depression $(\beta=.27, \mathrm{p}<.001)$, and lower levels of life satisfaction $(\beta=-.47, \mathrm{p}<.001)$. No significant path was found between integrity and 
Forgiveness and late life functioning

subjective health $(\beta=.11, p=.07)$ or between despair and subjective health $(\beta=-.08, \mathrm{p}=$ .18).

Finally, the direct pathways from forgiveness of others to depression, life satisfaction and subjective health were added to the model which resulted in a fully saturated partial mediational model. Indirect effects were tested (see Table 2). All indirect paths (through integrity and through despair) from forgiveness of others to depression and from forgiveness to life satisfaction were significant. The initial direct effect of forgiveness on depression $(\beta=-$ $.31)$ and on life satisfaction $(\beta=.31)$ decreased to respectively $\beta=-.20$ and $\beta=.15$ when adding the integrity and despair pathways. There were no significant indirect effects from forgiveness to subjective health through integrity and despair. The direct association between forgiveness and subjective health remained significant and largely undiminished $(\beta=.15, \mathrm{p}<$ $.01)$. In a final step, the two non-significant paths between subjective health and integrity on the one hand and despair on the other hand were removed. The trimmed model showed an excellent fit $\chi^{2}(2)=3.56$, RMSEA $=.05(90 \%$ C.I. $=[.00 ; .13])$, CFI $=.99$, SRMR $=.03$. (Figure 1). The final model explains $21 \%$ of the variance in depressive symptoms, $35 \%$ of the variance in life satisfaction, $7 \%$ of the variance in despair, $5 \%$ of the variance in integrity, and $3 \%$ of the variance in subjective health.

\section{Discussion}

The first aim of this study was to investigate whether the developmental task of integrity/despair mediated the expected negative relationship between forgiveness of others and depression in an elderly population and thus replicate earlier findings. Secondly, we wanted to extend this research question to other aspects of functioning, namely life satisfaction and subjective health. We expected that both variables would show a positive relationship with forgiveness of others and assumed that integrity and despair would also mediate the relationships of forgiveness of others with life satisfaction and subjective health.

In regard to our first objective, forgiveness of others was indeed negatively related to depression in our sample of elderly individuals, and this relationship was significantly mediated by integrity and despair, thus confirming our hypothesis. This is in line with prior research on the forgiveness - depression relationship in student samples (Brown, 2003), healthy adults (Toussaint et al., 2008) and elderly individuals (Dezutter et al., 2016). This result also provides additional support for previous findings on the resolution of the developmental task of integrity and despair as an explanatory mechanism for the inverse 
association between forgiveness of others and depression in elderly adults (Dezutter et al., 2016). Elderly individuals who are more forgiving, suffer less from depressive symptoms. Furthermore, forgiving older adults seem to be better equipped to resolve the late life developmental task, leading to a more facile achievement of integrity and less feelings of despair, both associated with the occurrence of depressive symptoms.

Considering the association with life satisfaction, the direct effects model showed a significant positive relationship with forgiveness of others, confirming our hypothesis. As suggested by prior research, having a forgiving disposition seems to come with a more content view on one's life (e.g., Thompson et al., 2005), especially for older adults (Toussaint et al., 2001). Our study additionally shows that this relationship is mediated by integrity and despair. Given the importance of ego-integrity in this life stage according to Erikson, and the facilitating role of forgiveness in reaching this desired state, being forgiving entails an important improvement on life satisfaction for elderly individuals. Forgiveness of others was also positively related with subjective health but contrary to our expectations, integrity and despair were not significant mediators in this relationship.

In sum, we found similar mediational relationships for the outcome variables depressive symptoms and life satisfaction, but only direct effects for the outcome subjective health. A possible explanation might be that subjective health, as a construct, is situated at the intersection of mental and physical health, and the reaching of ego-integrity might not have the same influence on physical components of late life functioning as it does on psychological components. This is in line with Erikson's developmental model that focuses on psychosocial themes, but not on physical health. Other potential mediators might play a more profound role in the relation between forgiveness and health-related outcomes. Possible aspects within the social realm like social support, quality of relationships, or loneliness might function as mediators between forgiveness and health and earlier studies in other age groups seem to affirm this idea. Attachment, conflict resolution, and relationship quality have also been shown to mediate the relation between forgiveness and health (e.g., Lawler, et al., 2005; Worthington \& Scherer, 2007). Social aspects as underlying mechanisms in the relation between forgiveness and late life health also fit within gerontological theorizing. The socioemotional selectivity theory (Carstens, 1992), for example, states that engaging in fewer but more valuable social interactions and meaningful relationships can be an optimal coping strategy for successful aging. Forgiveness might then be a valuable tool that stimulates the development of meaningful relationships resulting in better health. Future research might 
Forgiveness and late life functioning

measure these social variables and examine their ability to explain the forgiveness and health relationship in late life.

Our research findings seem to imply that having a forgiving attitude facilitates the developmental task of achieving ego-integrity in late life. Since ego-integrity involves coming to terms with regrets, painful experiences, and feelings of hatred, as well as resolving past conflicts, a forgiving attitude might indeed be a strength for elderly adults. Cultivating this strength might diminish feelings of despair and stimulate a more optimal life functioning.

\section{Limitations}

Although our study points to the importance of forgiveness of others as a protective factor against depression and a promoter of well-being and health in late life, in addition to deepening the understanding of the integrity/despair mechanisms underlying these connections, some limitations merit comment. First, due to the cross-sectional nature of the study, conclusions cannot be drawn regarding directionality. Previous research provided evidence for a relationship between well-being and a subsequent increase in forgiveness (e.g., Bono, McCullough, \& Root, 2007), implying the possibility of bi-directionality in the forgiveness - satisfaction relationship. Moreover, future longitudinal studies could indicate that whether one reaches ego-integrity in late life or not has an impact on one's forgivingness and, subsequently, on one's well-being. Second, our study focused on forgiveness of others, which is only one of multiple dimensions of the construct. Future research could further investigate whether other types of forgiveness have the same associations with our outcome variables. For example, research suggests a negative association between proactive forgiveness and life satisfaction in late life (Toussaint et al., 2001). Third, our study used selfreport measures for the different constructs and is as such susceptible to social desirability bias, especially since the questions were read out loud and responses were made verbally. Yet, research suggests that self-report measures of forgiveness do predict actual behavior (Thompson et al., 2005). The measures of forgiveness, subjective health, and integrity were necessarily brief to accommodate respondent burden limitations in this elderly sample and consequently showed modest levels of reliability. Last, this sample may not be representative of the elderly population in nursing homes. Elderly individuals that were more depressed, less satisfied, or in poorer health might have been less inclined to participate. Thus, high functioning elderly participants could be overrepresented in our sample. This is reflected in a low average score on our depression measure (GDS: $M=1.52, S D=1.86$ ). Moreover, for pragmatic reasons we excluded elderly individuals who suffered from cognitive, speech 
and/or hearing impairment. Since the attainment of ego-integrity depends on the capacity to overview and reflect on one's passed life, it could be interesting to explore whether the same models apply in elderly individuals with cognitive decline.

\section{Practical Implications}

Achieving a healthy balance between integrity and despair is according to Erikson a core tenet of optimal psycho-social functioning in late life. Several studies affirmed that being able to achieve ego-integrity is related with positive functioning in elderly adults (e.g., Westerhof, Bohlmeijer, \& McAdams, 2015). Our findings affirm this and show that the ability to forgive might facilitate the developmental task of finding ego-integrity and might avoid experiences of severe despair. Given the importance of forgiveness for coping with this late life developmental task, promoting or strengthen a forgiving attitude might stimulate ego-integrity and enhance late life functioning. Different intervention models to promote forgiveness have been constructed and implementing these models with elderly individuals might improve health and happiness. Enright developed a process model of forgiveness (Enright \& Fitzgibbons, 2000), consisting of four phases. The first 'uncovering phase' involves acknowledging the painful feelings pertaining to the offense. This is followed by a 'decision phase', during which the offended reflects on what forgiveness is, and whether they would commit to it. The 'work phase' follows, wherein the hurt person tries to understand the offender, which ultimately leads to acceptance. In a final 'discovery phase' unexpected positive consequences and healing are introduced. Another important model is Worthington's REACH model of forgiveness (Worthington, 2006) involving: (R)ecalling the hurt, (E)mpathizing, giving the (A)ltruistic gift of forgiving, (C)omitting to forgive and (H)olding on. Prior research has provided evidence for the efficacy of these and similar intervention models of forgiveness (Wade, Hoyt, Kidwell, \& Worthington, 2014).

Our findings additionally suggest that interventions aimed at resolving the developmental task of integrity/despair could be beneficial for elderly individuals. One intervention strategy that might promote ego-integrity is life review during which the elderly individual looks back on his/her life and memories with the help of a health professional (Butler, 1963). Alternatively, everything is written down in a 'life book'. Life review is to be differentiated from reminiscence by a more profound and evaluative focus, in the hope of leading participants to find meaning and peace in the process (Keall, Clayton, \& Butow, 2015). 
Forgiveness and late life functioning

Research has suggested life review as an effective treatment for late-life depression (Bohlmeijer, Smit, \& Cuijpers, 2003).

The present study provides evidence that forgiveness is connected to enhanced functioning through ego-integrity. The enhancement of both forgiveness and ego-integrity might be a particularly relevant goal in an intervention program for an elderly population.

Word count: 4609 


\section{References}

Allemand, M. (2008). Age differences in forgivingness: The role of future time perspective. Journal of Research in Personality, 42(5), 1137-1147. doi:10.1016/j.jrp.2008.02.009

Allemand, M., Hill, P. L., Ghaemmaghami, P., \& Martin, M. (2012). Forgivingness and subjective well-being in adulthood: The moderating role of future time perspective. Journal of Research in Personality, 46(1), 32-39. doi:10.1016/j.jrp.2011.11.004

Bohlmeijer, E., Smit, F., \& Cuijpers, P. (2003). Effects of reminiscence and life review on late-life depression: a meta-analysis. International Journal of Geriatric Psychiatry, 18(12), 1088-1094. doi:10.1002/gps.1018

Bono, G., McCullough, M. E., \& Root, L. M. (2007). Forgiveness, feeling connected to others, and well-being: Two longitudinal studies. Personality and Social Psychology Bulletin, 34(2), 182-195. doi:10.1177/0146167207310025

Brown, R. P. (2003). Measuring individual differences in the tendency to forgive: Construct validity and links with depression. Personality and Social Psychology Bulletin, 29(6), 759-771. doi:10.1177/0146167203029006008

Brown, R. P., \& Phillips, A. (2005). Letting bygones be bygones: Further evidence for the validity of the Tendency to Forgive Scale. Personality and Individual Differences, 38(3), 627-638. doi:10.1016/j.paid.2004.05.017

Butler, R. N. (1963). The life review: An interpretation of reminiscence in the aged. Psychiatry, 26(1), 65-76. doi:10.1080/00332747.1963.11023339

Carson, J. W., Keefe, F. J., Goli, V., Fras, A. M., Lynch, T. R., Thorp, S. R., \& Buechler, J. L. (2005). Forgiveness and chronic low back pain: A preliminary study examining the relationship of forgiveness to pain, anger, and psychological distress. The Journal of Pain, 6(2), 84-91. doi:10.1016/j.jpain.2004.10.012 
Forgiveness and late life functioning

Carstensen, L. L. (1992). Social and emotional patterns in adulthood: Support for socioemotional selectivity theory. Psychology and Aging, 7(3), 331-338. doi:10.1037/0882-7974.7.3.331

Charles, S. T., \& Carstensen, L. L. (2010). Social and emotional aging. Annual Review of Psychology, 61, 383-409. doi:10.1146/annurev.psych.093008.100448

Cheng, S.-T., \& Yim, Y.-K. (2008). Age differences in forgiveness: The role of future time perspective. Psychology and Aging, 23(3), 676-680. doi:10.1037/08827974.23.3.676

Collins, A.L., Glei, D.A., \& Goldman, N. (2009). The role of life satisfaction and depressive symptoms in all-cause mortality. Psychology and Aging, 24(3), 696-702. doi: $10.1037 / \mathrm{a} 0016777$

Cox, S. S., Bennett, R. J., Tripp, T. M., \& Aquino, K. (2012). An empirical test of forgiveness motives' effects on employees' health and well-being. Journal of Occupational Health Psychology, 17(3), 330-340. doi:10.1037/a0028314

Dezutter, J., Toussaint, L., \& Leijssen, M. (2016). Forgiveness, ego-integrity, and depressive symptoms in community-dwelling and residential elderly adults. The Journals of Gerontology Series B: Psychological Sciences and Social Sciences, 71(5), 786-797. doi:10.1093/geronb/gbu146

Dezutter, J., Wiesmann, U., Apers, S., \& Luyckx, K. (2013). Sense of coherence, depressive feelings and life satisfaction in older persons: a closer look at the role of integrity and despair. Aging \& mental health, 17(7), 839-843. doi:10.1080/13607863.2013.792780

Diener, E. D., Emmons, R. A., Larsen, R. J., \& Griffin, S. (1985). The satisfaction with life scale. Journal of personality assessment, 49(1), 71-75. 
Enright, R. D., \& Fitzgibbons, R. P. (2000). Helping clients forgive: An empirical guide for resolving anger and restoring hope. Washington, DC: American Psychological Association. doi:10.1037/10381-000

Enright, R. D., \& The Human Development Study Group. (1996). Counseling within the forgiveness triad: On forgiving, receiving forgiveness, and self-forgiveness. Counseling and values, 40(2), 107-126. doi:10.1002/j.2161-007X.1996.tb00844.x

Erikson, E. H. (1959). Identity and the life cycle: Selected papers. Psychological issues, 1, 1 171.

Erikson, E. H. (1982). The life cycle completed: A review. New York, NY: W. W. Norton.

Erikson, E. H., Erikson, J. M., \& Kivnick, H. Q. (1994). Vital involvement in old age. New York, NY: W. W. Norton.

Ermer, A. E., \& Proulx, C. M. (2015). Unforgiveness, depression, and health in later life: The protective factor of forgivingness. Aging \& mental health, 20(10), 1021-1034. doi:10.1080/13607863.2015.1060942

Fehr, R., Gelfand, M. J., \& Nag, M. (2010). The road to forgiveness: A meta-analytic synthesis of its situational and dispositional correlates. Psychological bulletin, 136(5), 894-914. doi:10.1037/a0019993

Friedberg, J. P., Suchday, S., \& Shelov, D. V. (2007). The impact of forgiveness on cardiovascular reactivity and recovery. International Journal of Psychophysiology, 65(2), 87-94. doi:10.1016/j.ijpsycho.2007.03.006

Friedberg, J. P., Tuvia, H. L., \& Cha, R. (2015). Forgiveness and health in patient populations. In L. L. Toussaint, E. L. Worthington, \& D. R. Williams (Eds.), Forgiveness and health: Scientific evidence and theories relating forgiveness to better health (pp. 107-121). the Netherlands: Springer. doi:10.1007/978-94-0179993-5_8 
Forgiveness and late life functioning

Green, M., DeCourville, N., \& Sadava, S. (2012). Positive affect, negative affect, stress, and social support as mediators of the forgiveness-health relationship. The Journal of Social Psychology, 152(3), 288-307. doi:10.1080/00224545.2011.603767

Griswold, C. L. (2007). Forgiveness: A philosophical exploration. Cambridge, England: Cambridge University Press.

Hearn, S., Saulnier, G., Strayer, J., Glenham, M., Koopman, R., \& Marcia, J. E. (2012). Between integrity and despair: Toward construct validation of Erikson's eighth stage. Journal of Adult Development, 19(1), 1-20. doi:10.1007/s10804-011-9126-y

Hill, P. L., \& Allemand, M. (2011). Gratitude, forgivingness, and well-being in adulthood: Tests of moderation and incremental prediction. The Journal of Positive Psychology, 6(5), 397-407. doi:10.1080/17439760.2011.602099

Ingersoll-Dayton, B., Torges, C., \& Krause, N. (2010). Unforgiveness, rumination, and depressive symptoms among older adults. Aging \& Mental Health, 14(4), 439-449. doi:10.1080/13607860903483136

Jongenelis, K., Gerritsen, D. L., Pot, A. M., Beekman, A. T., Eisses, A. M., Kluiter, H., \& Ribbe, M. W. (2007). Construction and validation of a patient- and user-friendly nursing home version of the Geriatric Depression Scale. International Journal of Geriatric Psychiatry, 22(9), 837-842. doi:10.1002/gps.1748

Keall, Clayton, \& Butow. (2015). Therapeutic life review in palliative care: A systematic review of quantitative evaluations. Journal of Pain and Symptom Management, 49(4), 747-761. doi:10.1016/j.jpainsymman.2014.08.015

Krause, N., \& Hayward, R. D. (2015). Aging, forgiveness, and health. In L. L. Toussaint, E. L. Worthington, \& D. R. Williams (Eds.), Forgiveness and health: Scientific evidence and theories relating forgiveness to better health (pp. 205-220). the Netherlands: Springer. doi:10.1007/978-94-017-9993-5_14 
Forgiveness and late life functioning

Lang, F.R., \& Carstensen, L.L. (1994). Close emotional relationships in late life: Further support for proactive aging in the social domain. Psychology and Aging, 9(2), 315324. doi:10.1037/0882-7974.9.2.315

Lawler, K. A., Younger, J. W., Piferi, R. L., Jobe, R. L., Edmondson, K. A., \& Jones, W. H. (2005). The unique effects of forgiveness on health: An exploration of pathways. Journal of behavioral medicine, 28(2), 157-167. doi:10.1007/s10865-005-3665-2

Lawler-Row, K., Hyatt-Edwards, L., Wuensch, K. L. and Karremans, J. C. (2011), Forgiveness and health: The role of attachment. Personal Relationships, 18: 170-183.

Lee, Y. (2000). The predictive value of self assessed general, physical, and mental health on functional decline and mortality in older adults. Journal of Epidemiology and Community Health, 54(2), 123-129. doi:10.1136/jech.54.2.123

Lowis, M. J., \& Raubenheimer, J. R. (1997). Ego integrity and life satisfaction in retired males. Counselling Psychology in Africa, 2(1), 12-23.

Maltby, J., Day, L., \& Barber, L. (2005). Forgiveness and happiness. The differing contexts of forgiveness using the distinction between hedonic and eudaimonic happiness. Journal of Happiness Studies, 6(1), 1-13. doi:10.1007/s10902-004-0924-9

McCullough, M. E., Bellah, C. G., Kilpatrick, S. D., \& Johnson, J. L. (2001). Vengefulness: Relationships with forgiveness, rumination, well-being, and the Big Five. Personality and Social Psychology Bulletin, 27(5), 601-610. doi:10.1177/0146167201275008

McCullough, M. E., Pargament, K. I., \& Thoresen, C. E. (2000). Forgiveness: Theory, practice, and research. New York: Guilford.

Offenbächer, M., Dezutter, J., Kohls, N., Sigl, C., Vallejo, M., Rivera, J., Bauerdorf, F., Schelling, J., Vincent, A., Hirsch, J., Sirois, F., Webb, J., Toussaint, L. (2016). Struggling with Adversities of Life: The Role of Forgiveness in Patients Suffering from Fibromyalgia. Clinical Journal of Pain. doi: 10.1097/AJP.0000000000000432. 
Forgiveness and late life functioning

Seybold, K. S., Hill, P. C., Neumann, J. K., \& Chi, D. S. (2001). Physiological and psychological correlates of forgiveness. Journal of Psychology and Christianity, 20(3), $250-259$.

Silton, N.R., Flannelly, K.J., Galek, K., \& Flannelly, L.T. (2010). Forgiveness, hostility, and subjective health. Gerontologist, 50, 4 .

Sorkin, D. H., \& Rook, K. S. (2006). Dealing with negative social exchanges in later life: Coping responses, goals, and effectiveness. Psychology and Aging, 21(4), 715-725. doi:10.1037/0882-7974.21.4.715

Steiner, M., Allemand, M., \& McCullough, M. E. (2011). Age differences in forgivingness: The role of transgression frequency and intensity. Journal of Research in Personality, 45(6), 670-678. doi:10.1016/j.jrp.2011.09.004

Tenklova, L., \& Slezackova, A. (2016). Differences between self-forgiveness and interpersonal forgiveness in relation to mental health. Journal of the Indian Academy of Applied Psychology, 42(2), 282-290.

Thompson, L. Y., Snyder, C. R., Hoffman, L., Michael, S. T., Rasmussen, H. N., Billings, L. S., ... Roberts, D. E. (2005). Dispositional forgiveness of self, others, and situations. Journal of personality, 73(2), 313-360. doi:10.1111/j.1467-6494.2005.00311.x

Torges, C., Ingersoll-Dayton, B., \& Krause, N. (2013). Forgiving and feeling forgiven in late adulthood. The International Journal of Aging and Human Development, 76(1), 2954. doi:10.2190/AG.76.1.b

Tornstam, L. (2005). Gerotranscendence: A developmental theory of positive aging. New York, NY: Springer Publishing Company.

Toussaint, L. L., Williams, D. R., Musick, M. A., \& Everson, S. A. (2001). Forgiveness and health: Age differences in a US probability sample. Journal of Adult Development, 8(4), 249-257. doi:10.1023/A:1011394629736 
Toussaint, L. L., Williams, D. R., Musick, M. A., \& Everson-Rose, S. A. (2008). Why forgiveness may protect against depression: Hopelessness as an explanatory mechanism. Personality and Mental Health, 2(2), 89-103. doi:10.1002/pmh.35

Vaillant, G. E. (2008). Aging well: Surprising guideposts to a happier life from the landmark study of adult development. Boston, MA: Little, Brown and Company.

Van Hiel, A., \& Vansteenkiste, M. (2009). Ambitions fulfilled? The effects of intrinsic and extrinsic goal attainment on older adults' ego-integrity and death attitudes. International Journal of Aging \& Human Development, 68(1), 27-51. doi:10.2190/AG.68.1.b

Van Lange, P. A. M., Otten, W., De Bruin, E. M. N., \& Joireman, J. A. (1997). Development of prosocial, individualistic, and competitive orientations: Theory and preliminary evidence. Journal of Personality and Social Psychology, 73(4), 733-746. doi:10.1037//0022-3514.73.4.733

Wade, N. G., Hoyt, W. T., Kidwell, J. E., \& Worthington Jr, E. L. (2014). Efficacy of psychotherapeutic interventions to promote forgiveness: A meta-analysis. Journal of Consulting and Clinical Psychology, 82(1), 154-170. doi:10.1037/a0035268.

Westerhof, G., Bohlmeijer, E., \& McAdams, D. (2017). The relation of ego integrity and despair to personality traits and mental health. Journal of Gerontology: Psychological Sciences, 72, 400-407.

Wilson, T., Milosevic, A., Carroll, M., Hart, K., \& Hibbard, S. (2008). Physical health status in relation to self-forgiveness and other-forgiveness in healthy college students. Journal of Health Psychology, 13(6), 798-803. doi:10.1177/1359105308093863

Witvliet, C. V. O., Ludwig, T. E., \& Vander Laan, K. L. (2001). Granting forgiveness or harboring grudges: Implications for emotion, physiology, and health. Psychological Science, 12(2), 117-123. 
Forgiveness and late life functioning

Wong, T. P. (2012). The human quest for meaning: Theories, research, and applications. New York, NY: Routledge.

Worthington Jr, E. L. (2006). Forgiveness and reconciliation: Theory and application. New York, NY: Routledge.

Worthington, E. \& Scherer, M. (2004) Forgiveness is an emotion-focused coping strategy that can reduce health risks and promote health resilience: theory, review, and hypotheses, Psychology \& Health, 19:3, 385-405, DOI: $10.1080 / 0887044042000196674$.

Worthington Jr, E. L., \& Wade, N. G. (1999). The psychology of unforgiveness and forgiveness and implications for clinical practice. Journal of Social and Clinical Psychology, 18(4), 385-418. doi:10.1521/jscp.1999.18.4.385 
Table 1

Pearson Correlations among the Study Variables and Cronbach's alpha's (along the Diagonal)

\begin{tabular}{|c|c|c|c|c|c|c|c|}
\hline Variables & $\begin{array}{c}\text { Mean } \\
{[S D]}\end{array}$ & Forgiveness & $\begin{array}{l}\text { Depressive } \\
\text { symptoms }\end{array}$ & $\begin{array}{l}\text { Satisfaction } \\
\text { with Life }\end{array}$ & $\begin{array}{l}\text { Subjective } \\
\text { Health }\end{array}$ & Integrity & Despair \\
\hline Forgiveness & $2.97[.81]$ & .65 & $-.31^{* *}$ & $.31^{* *}$ & $.18^{* *}$ & $.23^{* *}$ & $-.26^{* *}$ \\
\hline $\begin{array}{l}\text { Depressive } \\
\text { symptoms }\end{array}$ & $\begin{array}{c}1.52 \\
{[1.86]}\end{array}$ & & .77 & $-.61^{* *}$ & $-.38^{* *}$ & $-.35^{* *}$ & $.39^{* *}$ \\
\hline $\begin{array}{l}\text { Satisfaction } \\
\text { with Life }\end{array}$ & $3.34[.71]$ & & & .77 & $.29^{* *}$ & $.38^{* *}$ & $-.56^{* *}$ \\
\hline $\begin{array}{l}\text { Subjective } \\
\text { Health }\end{array}$ & $2.59[.61]$ & & & & .59 & $.14^{*}$ & $-.14^{*}$ \\
\hline Integrity & $3.64[.52]$ & & & & & .67 & $-.33^{* *}$ \\
\hline Despair & $1.57[.73]$ & & & & & & .74 \\
\hline
\end{tabular}


Table 2

Standardized Indirect Effects of Forgiveness through Integrity/Despair on Depression, Life Satisfaction and Subjective Health in Elderly Adults

\begin{tabular}{lccc}
\hline Indirect Effect Pathway & Depressive symptoms & Satisfaction with Life & Subjective Health \\
\hline $\begin{array}{l}\text { Indirect effect through } \\
\text { Integrity }\end{array}$ & $-.05^{*}$ & $.05^{*}$ & -.02 \\
$\begin{array}{l}\text { Indirect effect through } \\
\text { Despair }\end{array}$ &.$- .06^{*}$ & $.11^{* *}$ & .01 \\
\hline
\end{tabular}

Notes: ${ }^{*} P<.01 ;{ }^{* *} P<.001$. 


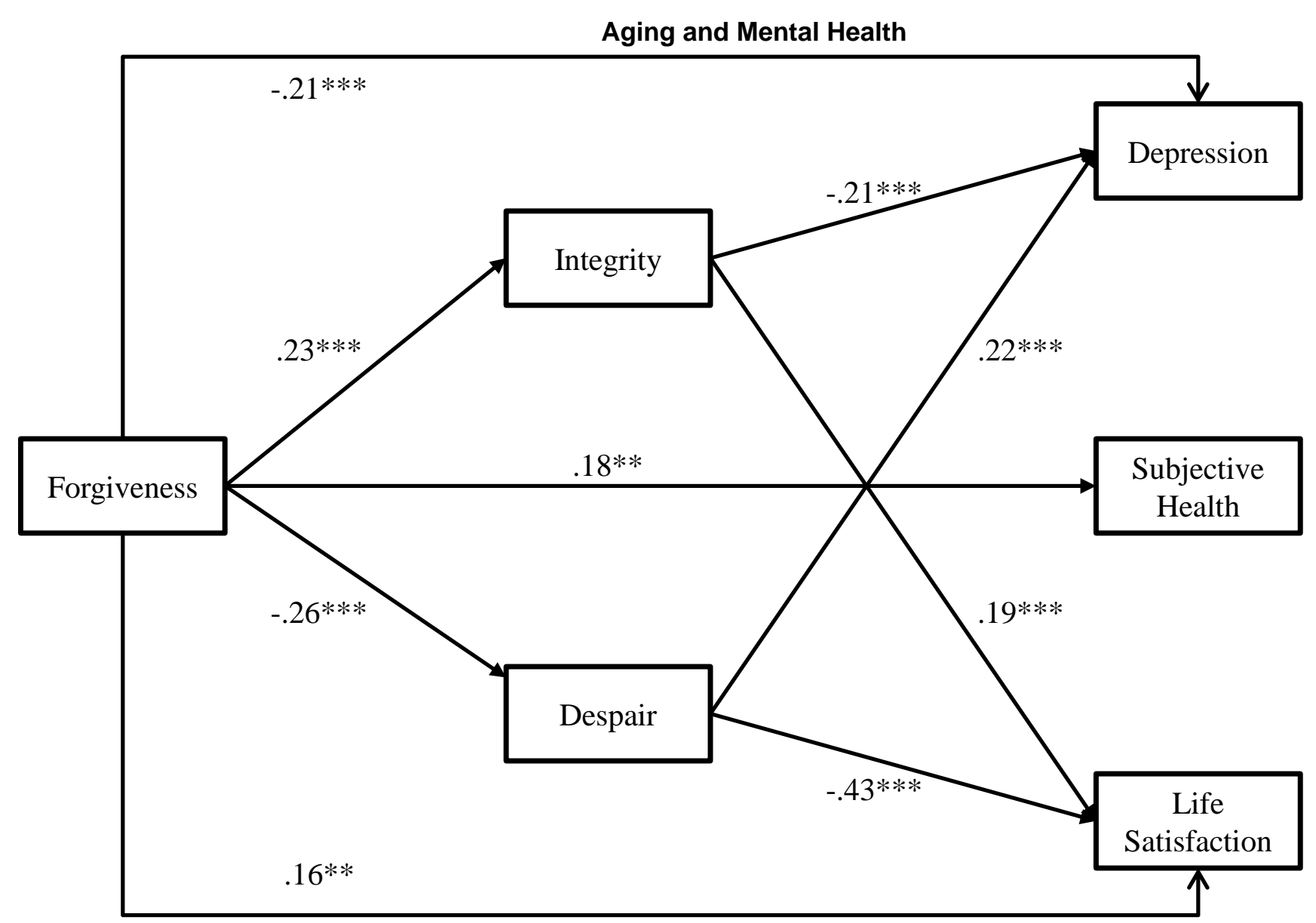

Figure 1. Path model for associations of forgiveness with depression, subjective health, and life satisfaction with integrity and despair as mediators of these associations. Error terms and covariances not shown. All coefficients are standardized. $* * \mathrm{p}<.01, * * * \mathrm{p}<.001$. 